\title{
Online Yaoi Fanfiction and Explorations of Female Desire through Sexually Exploited Male Bodies
}

\author{
Shweta Basu \\ Ph. D Research Scholar, Department of English, Jadavpur University. \\ E-mail: bluezyo8@gmail.com
}

\begin{abstract}
This essay will try to trace the phenomena of rape, dub-con (dubious consent), and non-con (non consent) as literary expressions of sexual violence which find their graphic and image-laden expression in anglophoneyaoi (fiction centred upon male homoerotic relationship (s) in the Japanese anime/manga context) fanfictions (fiction written by fans based on an extant work). Through my work, I try to delve into the question of consent and the rationale of such literary acts through fan ethnography. Also there is the fiction-based otherization of the authorial self as fanfiction is written purely for the pleasure (often masturbatory) of the author and the intended and implied audience (the yaoifanbase) who, while harboring and finding pleasure in such fantasies, do not subscribe to such notions in real life nor would they enjoy to be in such situations. The essay also deals with the question of how gay men are represented in such texts and their discomfort in such representations, where their bodies and sexuality are produced and consumed as tools of entertainment for women. These erotic texts exclusively cater to the female psychosexuality, as they are produced by and for women. Since in yaoi texts no involvement of the female body per se hence the pleasure is derived from a mental correlation. The fanbase of such work is also huge, centered around the rotten girls/fujoshi culture.
\end{abstract}

Keywords: rape, dub-con, non-con, yaoi, fanfiction, fan ethnography, pornography, aesthetic beauty, male homoerotic, derivative artworks.

This paper deals with yaoi fanfiction, that is male homoerotic fanfiction based on anime/manga texts. Fanfiction can roughly be defined as fiction written by fans, based upon an extant fictional universe and the relevant set of characters, who can either be reworked into an alternate universe or be woven into a possible continuation of the source storyline. ${ }^{i}$ Born with the purpose of paying homage to the source, this adaptation is part of the universal attempt at keeping a story going, and weaving new stories with characters we can relate to. The origins of fanfictions can be traced in the Graeco-Roman dramaturgy, where existing popular narratives were given newer interpretations by different dramatists. ${ }^{\text {ii }}$ The practice of fanfiction came into being in the

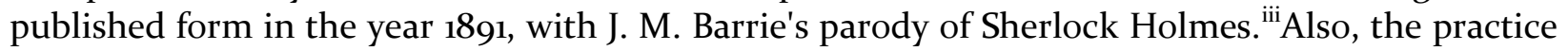
of writing "metafiction" or self-conscious fiction based on other, older published texts, like Rhys's Wide Sargasso Sea written in connection to Jane Eyre, or Joyce's Ulysses being a modern retelling of Homer's Odyssey, can be seen to be part of the wider purview of fanfiction, just as E.L. James' Fifty Shades of Grey had its inception in being a Twilight fanfic. ${ }^{\text {iv }}$ Same is true with the writing of "pastiches", where an author emulates the style and often stories of a literary predecessor, as with Barrie's Sherlock Holmes story.

(C) AesthetixMS 2020. This Open Access article is published under a Creative Commons Attribution Non-Commercial 4.o International License (http://creativecommons.org/licenses/by-nc/4.o/), which permits non-commercial re-use, distribution, and reproduction in any medium, provided the original work is properly cited. For citation use the DOI. For commercial re-use, please contact editor@rupkatha.com. 
Yaoi, also known as boys' love, or BL is a genre of fiction/fictional media that originated in Japan, characterized by its featuring of homoerotic relationships between male characters. Typically created by women authors for a female audience, it is distinct from the homoerotic fiction/media that is marketed to gay male audiences (such as bara), but yaoi also attracts male readers. ${ }^{\mathrm{v}}$

Yaoi can span across a wide range of media, including original manga or doujinshi, anime, drama CDs, novels (literary or visual), games, and fan production (such as fanfiction of media that is originally non-yaoi). Yaoi is defined by its characteristic practice of pairing the male characters in relationships according to two main roles. One is the seme who is the sexual top or active pursuer, and the other is the uke, who is the sexual bottom or passive pursuant ${ }^{\mathrm{vi}}$ (which is comparable to the ancient Greek practice of erastes and eromenos, the lover and the beloved in an established male homosexual relationship) ${ }^{\text {vii }}$.

Yaoi's origins come from both fan culture and commercial publishing. The term yaoi dates back to doujinshi culture of the late 1970s to the early 1980s. It is basically a portmanteau of the words "yamanashi ochinashi iminashi" (which in Japanese means no climax, no point, no meaning). It also has a parody origin that explains the term to be a portmanteau of "yamete oshiri ga itai" (which can be translated as, stop my ass hurts, referring to the anal sex tradition practised between homosexual men) ${ }^{\text {viii }}$. Yaoi was then a self-deprecating way of referring to amateur fan works that parodying the mainstream manga and anime by depicting their male characters in vague or explicitly sexual situations. Yaoi themes like social taboos, rape, physical or sexual violence, sexually insinuative humour etc, are also present in non-yaoi anime/manga, hence they easily lend themselves to such interpretations by fans while they write yaoi fanfictions based on them, as they tease out any possible homoerotic subtext, or create their own interpretation or simply imagine it on their own, without there being any basis of the same character dynamics within the source. Fanfictions also challenge the apparently climaxless, pointless, and meaningless storytelling techniques that were characteristic to initial yaoi, through their explorations of deviant sexuality, in the forms of paedophilia, BDSM, different kinds of kinks, incest and sexual violence, such as rape, whether in a conscious or drug-induced (using love potion or aphrodisiacs) situation. One sub-genre of yaoi pornfic is "porn what plot", or "porn without plot" which is self-explanatorily meant to be masturbatory content, is in tune with Helene Cixous' idea of the "l'ecriture feminine" or feminine fiction, in her essay "The Laugh of The Medusa"which is where women write their bodies (which practice is replaced here, and defamiliarized by the overarching presence of male bodies, however the expression of deviant desires remains similar).Writing, accordimg to Cixous,can cater to women's masturbatory impulse, by allowing them to celebrate their desires without shying away from them as society expects them to. ${ }^{\mathrm{x}}$

Most of the yaoi fans are either teenage girls or young women. In Japan, female fans of yaoi are called fujoshi, referring etymologically to the observation that a woman enjoying fictional gay content is "rotten", therefore too ruined to be married. The term "fujoshi" carried the connotation of being a "fallen woman", therefore emphasizing the self-awareness of fans that the practice of yaoi is both perverse and subversive in nature. ${ }^{\mathrm{xi}}$ The male equivalent of this term is fudanshi. The terms were initially coined by the online bulletin board 2 channel in the early $2000 \mathrm{~s}$ as a derogatory insult. These were later reclaimed as self-descriptive terms, as deviant desires came to be embraced even more as fansplaining.com's survey of content available at archiveofourown.org would show. Out of 7610 fanfiction writers who took their survey, around 6550 preferred hurt-comfort, which genre more than often features non-con or dub-con. ${ }^{\text {xii }}$

Shoujo manga stories that featured romances between boys or young men began to be commercially published in Japan from the mid-1970s, and soon enough, they became part of their 
own genre. However, the spread of yaoi though the Western fan-communities is generally linked to the Western slash fiction community that pre-existed. In the mid-1980s, fan translations of the manga series From Eroica with Love began circulating through the slash community via amateur press associations, which went on to create a "tenuous link" between the genres of slash and yaoi. ${ }^{\text {xiii }}$

Albeit the increasingly overlapping associations between Anglophone online yaoi fandom with that of online slash fandom, slash fiction has generically portrayed adult males, which according to Francesca Coppa are "overdetermined"xiv (physically muscular and buff, and emotionally catering to the social norms of masculinity, which come to be subverted through the storytelling), whereas yaoi follows the aesthetic of the bishounen (or the beautiful boy, often prepubescent, and even as adults, emphasizing upon their effeminate beauty or lithe features). ${ }^{\mathrm{xv}}$ However, according to Jessica Bauwens-Sugimoto, there exists a tendency in both yaoi and slash fandoms towards the disparaging of the other fandoms' heteronormativity, their potential for subversiveness or even their potential for enjoyment, as if this sense of loving and practicing sexual deviance is superior to the other normative forms of love and subsequent artistic representations. ${ }^{\text {xvi }}$

Yaoi fanfictions can deal with the issues of sexual pleasure derived from sexual violence/assault, through various genres and approach. In addition to the "regular" genres, like fantasy fiction, science fiction, wuxia/xianxia (Chinese martial universe), thriller etc., which, for a given fanfiction are usually determined by the source work they are based on, there are a few genres that are specifically associated with fanfictions. Often, they tend to overlap. Such genres, amongst others, like hurt-comfort (one character us hurt and the other comforts him), lemon (steamy sex scenes), smut (sex for purely pornographic purpose, often violent), would also include angst, which is the most used one in this regard. This genre causes the narrative to have an overall angsty mood, where the pivotal characters are either brooding, sad, or in anguish. This oftentimes provides the perfect entry-point for the healing cock, where there may be a sudden burst of emotions from either the top or the bottom resulting in sexual violence being perpetrated, generally by the top on the bottom (which may be seen explicitly as rape or non-con), or there may be the presence of intoxicants which lays bare the conduits of hitherto repressed emotions of both the partners, or the vulnerable state of the intoxicated bottom may propel the top to assume consent (hence dubious consent) and act on his own desires that he was too afraid to own up till then. The endings of both dub-con and non-con fics generally resolve the problems with such assumptions by the bottom reciprocating the top's feelings, which is highly unlikely in a real-life scenario.

Rape as a backstory for a yaoi fanfiction maybe dealt with in many ways. According to TVtropes.org, a rape backstory, which may or may not feature in the overt plot of the fanfiction, is a "popular way to establish a character as having a motivation for their depression, angst, distrust of others, and other anti-social tendencies." ${ }^{\text {xvii }}$ Sometimes, in a hurt-comfort scenario, it may be used as a pretext to garner empathy from the "true" romantic interest, who breaks this sarcastic or scared outer shell of the "bottom", by making love to him, referred to as the "healing cock" by Francesca Coppa. ${ }^{\text {xviii }}$

Rape-fics can also feature rape as part of the main story, which may or may not be accompanied by major character death, where the protagonist dies, thereby escalating the violence. Non-con fics are fanfictions where the bottom is not consensual about being sexually penetrated by the top, it might be a rape, which although highly unlikely in real life, blossoms into love and may end up in the bottom forgiving the top (who is often intoxicated or under foreign mental influence) in the long run. Dub-con fics feature dubious consent on part of the bottom, using the trope "no means yes", or use of aphrodisiacs or mind-altering substances, which 
may make him crave sex uncharacteristically. ${ }^{\text {xix }}$ It can also involve the plot device, "rape or die", where the two male sexual partners need to force themselves to have sex with each other, without real consent or willingness, as some alien entity who demands it, either as punishment or selfpleasure, may kill them. ${ }^{\mathrm{xx}}$

Delving into the question of consent and the rationale of such literary acts through fan ethnography, Jess Joho, writing for the e-zine Mashable, smutty/erotic fanfiction ought to be celebrated as "only bastion of sexual exploration that makes a space for everyone, no matter who they are or what they like... (whether) women, LGBTQ folks, people of color", all whose sexual desires are other-ized by the "mainstream media, from movies to porn." Many teenagers have spoken to have explored nascent sexuality through smutty fanfiction. ${ }^{\text {xxi }}$ As critic Anne Jamison would put it in the same magazine article, "In communities ... where it's abstinence-only education, young people are getting actual information about sexuality in fanfiction," oftentimes "the only information about sexuality". While due to temporal constraints we are not able to analyse the relevance of such fictional expressions vis-a-vis the existing social theories of sexual violence within the wider purview of violence, we find that sexual violence in yaoi fanfiction is hinged upon is the fiction-based otherization of the authorial-self. Fanfiction is written purely for the pleasure (often masturbatory) of the author and the intended and implied audience (the yaoi fanbase) who, while harboring and finding pleasure in such fantasies, do not subscribe to such notions in real life nor would they enjoy being in such situations.

Mark McLelland's study of Japanese gay men deals with the question of how gay men feel discomfited by their representation in such texts where their bodies and sexuality are produced and consumed as tools of entertainment for women. As adolescent boys while growing physically and sexually, they saw such pop-media artifacts as creating impossible bodily standards for them, as all of them were not dashingly handsome or beautifully effeminate, which made them suffer from low self-esteem. However, the question of sexual exploration vs one sided homosexual "love" being thrust upon the other is not raised, nor found to be disturbing to them, since Japanese pornography has an existing trend, in both gay and straight porn, that the sexual recipient is not acting according to his/her will and words such as "iya", meaning "no", yamete -- "stop", "itai" -"it hurts" are frequently in use. ${ }^{\text {xii }}$

In these yaoi fanfictions, the performative male body which is key to the unfolding of the narratives, especially during sexual acts, does succumb to heterosexual gender roles, known as seme (the "active" top) and uke (the "passive" bottom). In sexually violent yaoi fanfiction, the male body of the uke performs the role of the traditional recipient, or the body which is violated, which may even include male pregnancy (mpreg), pheromones going out of control and animal estrous cycles (being in heat). Therefore the aestheticized and romanticized beautiful male body of the "bishounen" is at once made to play various roles that can range from pornography and wish-fulfilment to aesthetic beauty and differing ideas of "tough love", as often the victim falls in love with the assailant, and forgives his trespassing (which is highly unlikely in real life). Fanfictions, on the other hand depend on the praxis of morphing the extant texts into derivative artworks which transform the source content to suit the purposes of the yaoi fan-artists. While there is complete autonomy of imagination as there is no capitalist publishing culture that they must answer to, it also raises the question of violating the original authorial intention, as the authors, most famously the authors of Game of Thrones, Enders' Game, and The Vampire Chronicles, themselves sometimes take issue with such representations of characters and settings of their own. xxiii $^{2}$

These erotic texts exclusively cater to the female psychosexuality, as they are produced by and for women. Since in yaoi texts no involvement of the female body per se hence the pleasure is derived from a mental correlation. As the statistics of such sexually violent works as published on 
online fan-fiction communities would show, the fanbase of such work is also huge. The frequent use and popularity of such sexually violent scenarios, may be explained through French sociologist Pierre Bourdieu's concept of "habitus". xxiv

Habitus refers to the physical embodiment of the cultural capital, which stems from the ingrained skills, habits, and dispositions which come to define us over time, things that we learn from our life experiences, things that make us who we are. According to Boudieu, this is a "feel for the game" something that is inherent and instinctive, something that underlines our proficiency at the fields in which we excel. For fan-authors, this habitus is their connection to the source narrative that they base their fanfictions on, as well as their linguistic and cultural competence which allows them to shape and re-shape that extant narrative universe into something that expresses them and their choices, which in this particular case, involves sexual violence between the protagonists as an exploration of deviant desires. The only difference is that such taboo issues or criminal concerns/acts, do not necessarily derive out of a personal experience, but in tune with Sigmund Freud's psychoanalytic concept of "catharsis", this practice may help as a vent to the fanauthor's hurtful feelings about life, as many epilogues, prologues and author-rant sections of such fanfictions would show. ${ }^{\mathrm{xx}}$ Such imaginary situations help them work with their own feelings, that too anonymously, (since the authors generally post through handle names and mostly do not divulge their personal details) as, according to the usual scenario of the story, the hurt caused by the lover is generally followed by comforting the beloved and both ameliorating each other's hurt by lending an ear to each other. What is more interesting, is that this familiar trope of hurtcomfort gets a different kind of treatment based on the inherent sensibilities of the characters involved (as there is generally an attempt by the fans to be textually accurate regarding the character representation) or the sensitivity of the fan-author.

Bourdieu suggested that habitus allows individuals to find new solutions based on newer situations without having to deliberate in a calculated manner, which can explain how rant-fics (fanfictions that involve long personal monologues from the fan authors and used as a redemptive measure for mental disorders like social phobia or workplace/family stress) work. The fancommunity based on sexually violent yaoi fanfictions create given situations, where the fan-made pairings between the characters are not deliberated upon, yet are seen as natural. Each of these pairings has their own fanbase, based on the personal preferences of the fans, which in turn are based on their gut feelings and intuitions, which are culled from the interactions between the characters within the source narrative. Bourdieu's concept of habitus is collective and socially shaped, so are these yaoi pairings, and their sexual interactions.

For Coppa, bodies are the true protagonists for homoerotic fanfictions, because the physical touches and sexual explorations have their own semiotics and form a different sort of language for emotional communication, which is otherwise impossible for the "manly" characters trapped by the norms of patriarchy. The issues of physical/sexual violence which is then ameliorated by Coppa's idea of the "healing cock" through a hurt-comfort scenario, allows both the fan-author as well as the reader(s) of the fanfiction to explore the vulnerabilities and insecurities of the characters, both of the penetrator or the "lover", (who is not really a perpetrator in the legal sense as this is seen as an "act of love" which is later forgiven by the beloved) and the penetrated or the "beloved". Women fanfiction writers and readers often use heteronormative tropes where the "uke" plays the part of the woman in a relationship, or a sexual act, and like erotic fiction where the dashing heroes "force" or "claim" their love interests, they can imagine themselves in their shoes, minus the fear and the identification that might come with the involvement of a female body as in a Mills and Boon romance. Here the explorations are even more bold and candid, since the male body of the "penetrated" forms a comfortable 
defamiliarized distance from which the the fan-author can operate her desires, for a maximum impact.

This reworking of unfulfilled fantasies occurs through an inclusively female fan group (inclusive as in mostly female but since it is anonymous, other genders may also participate) "gift culture" between authors, proof-readers, moderators and more. ${ }^{\text {xxi }}$ Fanfiction is primarily a genre fraught with legal disputes regarding copyright claims from the authors of the source texts and it does not seek to make money out of the authorial labour. Therefore, it is a perfect literary location for such radically different reinterpretations, as it carries no pressure of garnering economic benefit or literary fame/career out of these works. The disclaimers that are in place can also keep away people who do not enjoy the presence of sexual violence underneath, so the creators and the readers of the texts know exactly what they want and how they want it.

To conclude, sexually explicit yaoi fanfictions give rise to a sexual utopia where the nittygritties of real-life consent do not work. They also provide a vent for many women to work out their own rape fantasies without being overtly engaged, as they would with the presence of a violated female body. ${ }^{\text {xvii }}$ The male bodies then provide a kind of buffer to provide a voyeuristic pleasure akin to that derived from pornography, which does not require direct involvement of the watcher's body. Also in case of dubious consent, or where the perpetrator assumes consent from the "victim" is clearly different from real life scenarios, as in fanfictions, the narratives cater to sexual fantasies of "not needing to communicate" or "the partner knowing more about me than I do myself" as well as "assuming control/domination/power-play" as it exists in the ouevre of sexual fantasies of women, whereas it in no way follows back to real life. People (fan authors/readers) assuming anonymity or "nonnies" (as they are more playfully called) ascertain that the real and the imagined, the public and the private remain mostly separate (unless they meet as people in conventions or informal meets as people). ${ }^{\text {xxiii }}$ This in no way, as some would fear, give a push to the existing evils of "rape culture", rather, as many rape survivors would agree, writing such fanfictions, or having such fantasies allowed them to cope with such violent external forces.

\section{Endnotes}

i, See Jamison (2013) for a wider discussion on the topic.

${ }^{i i}$ See Kahane (2016) for a more detailed discussion on the topic.

iii See Ilias (2018).

${ }^{\text {iv }}$ See Brennan \& Large (2014).

vSee McLelland (2005).

viZanghellini (2009).

vii Lear(2014).

viii McLelland (2000).

${ }^{\text {ix }}$ Porn Without Plot. TVTropes.org.

${ }^{x}$ Cixous(1976).

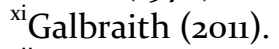

${ }^{x i i} \operatorname{Klink}(2017)$.

xiii Suzuki (1998).

${ }^{\text {xiv }}$ Coppa (2018).

${ }^{\mathrm{xv}}$ Sasaki(2013).

${ }^{x v i}$ Bauwens-Sugimoto(2011).

xvii Rape as Backstory. TVTropes.org.

xviii Coppa (2018).

xix "No" Means "Yes". TVTropes.org. 
${ }^{\mathrm{xx}}$ Sexual Harassment and Rape Tropes. TVTropes.org.

xxi Joho (2018).

${ }^{x x i i}$ McLelland (2005). Male homosexuality.

xxiii $\operatorname{Lipton}(2014)$.

${ }^{\text {xxiv }}$ Bourdieu(1990).

${ }^{\mathrm{xxv}}$ Lawtoo (2018).

${ }^{\mathrm{xxvi}}$ Riley(2015).

${ }^{x x v i i}$ Keft-Kennedy (2008).

xxviiii Brennan (2014).

\section{References}

Bauwens-Sugimoto, J. (2011). Subverting masculinity, misogyny, and reproductive technology in SEX PISTOLS. Image \& Narrative, 12(1), 1-18.

Bourdieu, P. (1990). Structures, habitus, practices. The logic of practice, 52-65.

Brennan, J. (2014). 'Fandom is full of pearl clutching old ladies': Nonnies in the online slash closet. International Journal of Cultural Studies, 17(4), 363-380.

--- \& Large, D. (2014). 'Let's Get a Bit of Context': Fifty Shades and the Phenomenon of 'Pulling to Publish'in Twilight Fan Fiction. Media International Australia, 152(1), 27-39.

Cixous, H., Cohen, K., \& Cohen, P. (1976). The laugh of the Medusa. Signs: Journal of Women in Culture and Society, $1(4), 875-893$.

Coppa, F. (2018). Slash/Drag: Appropriation and Visibility in the Age of Hamilton. A Companion to Media Fandom and Fan Studies, 189.

Galbraith, P. W. (2011). Fujoshi: Fantasy play and transgressive intimacy among "rotten girls" in contemporary Japan. Signs: Journal of Women in Culture and Society, 37(1), 219-240.

Ilias, N. (2018). Reimagining Sherlock Holmes: A Study in Gender Performativity.

Jamison, A. (2013). Fic: Why fanfiction is taking over the world. BenBella Books, Inc..

Joho, J. (2018, November 21). How erotic fanfiction lets women explore their sexuality without shame. Retrieved August 27, 2020, fromhttps://in.mashable.com/entertainment/1217/how-erotic-fanfictionlets-women-explore-their-sexuality-without-shame

Kahane, A. (2016). Fan fiction, early Greece, and the historicity of canon. Transformative Works and Cultures, 21.

Keft-Kennedy, V. (2008). Fantasising masculinity in Buffyverse slash fiction: Sexuality, violence and the vampire. Nordic Journal of English Studies, 7(1), 49-80.

Klink, F. (2017, May 30). Towards a Definition of "Fanfiction". Retrieved August 26, 2020, from https://www.fansplaining.com/articles/towards-a-definition-of-fanfiction

Lawtoo, N. (2018). Violence and the Mimetic Unconscious (Part One): The Cathartic Hypothesis: Aristotle, Freud, Girard. Contagion, 25, 159-192.

Lear, A. (2014). Ancient Pederasty. A Companion to Greek and Roman Sexualities, Malden, MA/Oxford/Chichester, 106-131.

Lipton, J. D. (2014). Copyright and the Commercialization of Fanfiction. Hous. L. Rev., 52, 425.

McLelland, M. (2000). No climax, no point, no meaning? Japanese women's boy-love sites on the internet. Journal of Communication Inquiry, 24(3), 274-291.

--- (2005). Male homosexuality in modern Japan: Cultural myths and social realities. Routledge.

--- (2005). The World of Yaoi: The internet, censorship and the global 'Boys 'Love'fandom. Australian Feminist Law Journal, 23(1), 61-77.

"No" Means "Yes". Retrieved August 27, 2020, from https://tvtropes.org/pmwiki/pmwiki.php/Main/NoMeansYes

Porn Without Plot. Retrieved August 27, 2020, from https://tvtropes.org/pmwiki/pmwiki.php/Main/PornWithoutPlot?from=Main.PornWithExcusePlot 
Rape as Backstory. Retrieved August 26, 2020, from https://tvtropes.org/pmwiki/pmwiki.php/Main/RapeAsBackstory

Riley, O. (2015). Archive of Our Own and the Gift Culture of Fanfiction.Transformative Works and Cultures Sasaki, M. (2013). "Gender Ambiguity and Liberation of Female Sexual Desire in Fantasy Spaces of Shojo Manga and the Shojo Subculture". CTSJ: Journal of Undergraduate Research, 3(1), 4.

Sexual Harassment and Rape Tropes. Retrieved August 27, 2020, from https://tvtropes.org/pmwiki/pmwiki.php/Main/SexualHarassmentAndRapeTropes

Suzuki, K. (1998). Pornography or therapy? Japanese girls creating the Yaoi phenomenon. Millennium girls: Today's girls around the world, 243-267.

Zanghellini, A. (2009). Underage sex and romance in Japanese homoerotic manga and anime. Social E Legal Studies, $18(2)$, 159-177. 